\title{
Viajando por la periferia del Área Metropolitana de Guadalajara, México Entre la pasividad y la agencia
}

Fernando Calonge Reillo

Centro Universitario de Tonalá, Universidad de Guadalajara, México Correo electrónico: fercalonge@yahoo.es
Recibido

Junio de 2018

Aceptado

marzo de 2019

doi: $10.34096 /$ cas.i5o.4966

\section{Resumen}

La mayor parte de la literatura contemporánea sobre las movilidades se ha centrado en el análisis de las posiciones sociales de clase alta, como los hombres de negocio, académicos o profesionales. Para contrarrestar esta sobrerrepresentación, el presente artículo se concentra en las movilidades cotidianas de poblaciones subordinadas en el municipio periférico de El Salto, perteneciente al Área Metropolitana de Guadalajara, México. El artículo recoge los resultados de la observación etnográfica en la zona y de 40 entrevistas en profundidad para presentar las formas de viaje y movilidades de estas poblaciones subordinadas. Frente a la descripción de estas poblaciones a partir del paradigma de las movilidades, a las que se califica como confinadas o pasivas, el artículo presenta una gran cantidad de desplazamientos y modestas estrategias de movilidad que exigen una reconsideración de estas poblaciones por parte de la literatura.

\section{Travelling through the periphery of Guadalajara Metropolitan Area, Mexico. Between passivity and agency}

\begin{abstract}
While a great part of the contemporary literature on mobilities has focused on how privileged social positions held by businessmen, academics, and professionals define contemporary mobile society, this paper will focus on the everyday mobilities of subordinated and peripheral populations, using fieldwork data from El Salto, a county (municipio) in the periphery of the Guadalajara Metropolitan Area, Mexico. Presenting the range of displacements and movements performed by its inhabitants, this article contests the dominant view of subordinated populations within a mobile society, often described as confined or passive.
\end{abstract}

\section{Palabras clave}

México; Movilidades; Periferias; Identidad social; Exclusión social

\section{Key words}

Mexico; Mobilities; Peripheries; Social Identity; Social exclusion 


\section{Viajando pela periferia da área metropolitana de Guadalajara, México. Entre a passividade e agência}

\section{Resumo}

Palavras-chave

México; Mobilidades; Periferias; Identidade social; Exclusão

A maior parte da literatura contemporânea sobre mobilidade tem se centrado na análise dos posicionamentos sociais da classe alta: empresários, acadêmicos ou profissionais. Em contra desta sobre-representação, este artigo centra-se na mobilidade diária das populações marginalizadas no município periférico de El Salto, pertencente à área metropolitana de Guadalajara, México. O artigo reúne os resultados da observação etnográfica na área e os resultados de 40 entrevistas em profundidade para apresentar as formas de viagem e mobilidade dessas populações subordinadas. Contra as descrições do uso que o paradigma da mobilidade faz dessas populações, que as descreve como confinadas ou passivas, o artigo apresenta um grande número de deslocamentos e estratégias modestas de mobilidade que exigem uma reconsideração dessas populações pela literatura.

\section{Introducción}

La bibliografía más relevante del paradigma de las movilidades ha cambiado la forma tradicional de escribir e investigar en ciencias sociales (Cresswell, 2006; Elliot y Urry, 2010; Cresswell y Merriman, 2010; Büscher y Urry, 2011). Tomando como objeto de estudio las automovilidades, las movilidades de las elites capitalistas, o las implicaciones de las movilidades modernas para el surgimiento de la ciudadanía liberal, estos estudios han controvertido las discusiones clásicas sobre la estratificación social, el sujeto, la nación o el papel de la tecnología.

Buena parte de estas contribuciones tienen su origen en los países desarrollados, lo que ha condicionado que su objeto de reflexión se centrara en las elites empresariales, profesionales o universitarias, que se han convertido en el modelo de sujetos propios del presente estadio del capitalismo global. Estas figuras han quedado caracterizadas como flexibles, altamente móviles e incluso como desterritorializadas (Urry, 2004; Elliot y Urry, 2010). Sin embargo, también han existido llamamientos a considerar las movilidades de los grupos subordinados, aunque aquí los trabajos son menos numerosos y se han centrado en figuras cliché, que no son especialmente representativas, como los vagabundos o los refugiados. Lo común de este tipo de análisis es describir a estos sujetos como pasivos y sin la capacidad de decidir sobre sus propias movilidades y permanencias. Así, hay autores que los han retratado como condenados a permanecer anclados a un lugar al que, por otro lado, sienten como ajeno (Harvey, 1994; Hiernaux y Lindón, 2004; Rose, 2004; Boltanski y Chiapello, 2005), o bien como condenados a realizar viajes cotidianos o extraordinarios no deseados e inhabilitantes (Bauman, 1998; Cresswell, 2006; Jacquin, 2007). Como en otra parte ha animado a hacer Edensor (2011), es propósito de este artículo interpretar este tipo de movilidades de los subordinados por encima de la simple pasividad, por lo que se mostrará también cierta capacidad de decisión sobre las propias movilidades y permanencias.

Con el paso del tiempo, se han incorporado al debate académicos e investigaciones desde los países en desarrollo, lo que permite la inclusión de nuevas clases y posiciones sociales en el análisis. En este artículo se revisan algunos de estos casos, que ayudan 
a ampliar el tipo de sujetos, comportamientos y actitudes a ser estudiados desde el paradigma de las movilidades, en el contexto latinoamericano. Así, se incorporarán casos cotidianos en un entorno periurbano, lo que permitirá detectar nuevos sujetos distintos a los usualmente descritos por la literatura, y así completar el cuadro de las movilidades contemporáneas. Con ello se pretende mostrar la amplia heterogeneidad y multiplicidad de posiciones y sujetos subordinados y móviles, muchos de los cuales no pueden ser correctamente interpretados desde las iniciales consideraciones sobre la pasividad.

El artículo se basa en una investigación desarrollada entre octubre de 2013 y julio de 2014 en El Salto, uno de los municipios más lejano del Área Metropolitana de Guadalajara, donde se desarrollaron un total de 40 entrevistas en profundidad. En la elección de los sujetos de estudio se siguió la técnica de bola de nieve, aunque se intentó asegurar la inclusión en la muestra de la mayor diversidad posible en términos de los siguientes criterios estructurantes: género, edad, ocupación, hábitat de residencia, disponibilidad de automóvil y uso de transporte público. Con ello se consiguió cubrir la mayor gama de experiencias de movilidad de los sujetos subordinados en esta periferia. Asimismo, se desarrolló trabajo de campo etnográfico en las localidades de Las Pintas, El Verde, El Castillo, El Quince y la Cabecera Municipal, en escenarios tan variados como plazas públicas, un corredor industrial, los exteriores de planteles educativos y zonas interiores de las barriadas.

El artículo se divide en cuatro secciones. En la primera se sitúa el marco teórico necesario para enfocar las movilidades en la periferia urbana, especialmente en el contexto latinoamericano. La segunda parte ofrece una descripción del caso de estudio y de los recursos de movilidad que están a disposición de los habitantes. En la tercera parte se ofrece una serie de casos que muestran movilidades particulares que escapan a la imagen de inmovilidad, confinamiento o movilidad forzada como tradicionalmente han quedado retratados nuestros sujetos de estudio. En las conclusiones se enfatiza la necesidad de recuperar un relato sobre las movilidades que subraye la multiplicidad y heterogeneidad de las posiciones y sujetos sociales.

\section{El contexto para el estudio de las movilidades periféricas}

Como ya se ha mencionado, una buena parte de la bibliografía contemporánea sobre movilidades se centra en el estudio de las elites globales, que han sido consideradas como las que más fielmente representan las características del mundo presente. Se asume que sus estilos de vida establecen los cánones normativos sobre los comportamientos y valores del tiempo presente (Kellerman, 2006; Urry, 2007) frente al resto de sujetos, que tienden a quedar subordinados (Rose, 2004; Cresswell, 2006; Manderscheid, 2009). Según estas versiones, las elites globales viven de manera flexible y desterritorializada, lo que les permite estar en una búsqueda constante de nuevos y prometedores espacios y oportunidades.

Al mismo tiempo, se ha propuesto considerar las movilidades de otros grupos sociales para tener una perspectiva más completa e integral de las actuales movilidades (Cresswell, 2006; Adey, 2013). Para cubrir los sectores subordinados en el mundo de las movilidades se ha propuesto el estudio de grupos como los vagabundos (Bauman, 1998), refugiados (Cresswell, 2006) o los emigrantes por razones económicas (Appadurai, 1998). En estos casos, los sujetos subordinados han sido caracterizados como apresados en regímenes restrictivos de movilidad (Sibley, 2003; Kellerman, 2006), como inmovilizados (Boltanski y Chiapello, 2005), o como segregados (Rodgers, Beall y Kanbur, 2011) respecto de los epicentros de la vida socioeconómica de la urbe donde residen, consumen y trabajan las elites globales. Mientras que estas últimas 
son las verdaderamente móviles, aquellas otras figuras subordinadas estarían atrapadas espacialmente, condenadas a los estrechos límites de lo local (Bauman, 2003; Freudental-Pedersen, 2009), o bien obligadas a desplazarse por no ser bienvenidas en ninguna parte o por quedar encadenadas dentro de movilidades forzadas que sirven $y$ benefician a las elites (Kellerman, 2006; Pinder, 2011). En cualquiera de estos casos, las movilidades obligatorias serían ampliamente deshabilitantes, y limitarían la capacidad de los sujetos de actuar y decidir libremente (Soja, 2000; García Peralta, 2011). Como ha quedado asentado desde la introducción, este tipo de consideraciones implica que los sujetos subordinados son ampliamente pasivos y tienen muy escasas opciones de decidir libremente sobre el sentido de sus movilidades y permanencias.

Más recientemente se han incorporado trabajos que miran más allá de esas figuras de los refugiados o los vagabundos, y se enfocan en las poblaciones de bajos recursos de varias metrópolis en los países en desarrollo. Así, Melissa Butcher (2011) describe los viajes cotidianos de los jóvenes marginados de Delhi que están rodeados de sensaciones de frustración, temor o incomodidad. Por su parte, Shahnaz Huq-Hussain y Umme Habiba (2013) muestran cómo las mujeres de Dhaka son capaces de explorar sus limitadas opciones de movilidad para organizar sus viajes cotidianos. Al tiempo, Samanta y Roy (2013) estudian las experiencias de los porteadores de carros de transporte que quedan divididos, en su inserción en la metrópoli, entre la modernidad y la informalidad. Todas estas aportaciones permiten visualizar que las movilidades de los sujetos subordinados en los países en desarrollo exceden con mucho las interpretaciones tradicionales sobre su pasividad y, por el contrario, muestran momentos de agencia muy importantes. Con ello, se consigue modificar y complementar las visiones iniciales y unilaterales sobre las movilidades de los sujetos marginados.

En Latinoamérica, y en metrópolis como la Ciudad de México, Buenos Aires, Lima o Santiago, se cuenta un interés creciente por investigar los entornos y las condiciones sociales existentes en las periferias urbanas (Lindón Villoria, 2008; Fada, Jirón y Allen, 2000; Rodríguez y Arriagada, 2004; Sabatini y Brain, 2008; Jacquin, 2012; Jirón y Mansilla, 2014). Estos estudios analizan cómo los diferentes Estados fueron los principales responsables en el crecimiento de las periferias metropolitanas, al ser incapaces de acoger en los centros urbanos a las clases sociales subordinadas. Sin embargo, es desde la década de 1990 cuando el mercado cobra protagonismo, al generar la caótica ocupación de antiguos espacios rurales en el extrarradio metropolitano que siguen acogiendo a los habitantes subordinados. Esta expansión de las periferias de las metrópolis latinoamericanas se produce a expensas de tales poblaciones, que se ven condenadas a vivir en entornos muy precarios, lejanos y carentes de los más básicos servicios sociales. Así, los diversos estudios muestran cómo, en las periferias metropolitanas de ciudades como Lima, México, San Pablo o Buenos Aires, los habitantes han de enfrentarse a difíciles condiciones de vida y a muy complejas movilidades y desplazamientos que amenazan el desarrollo de sus vidas cotidianas.

A la hora de analizar los retos a la reproducción de los hogares subordinados en el contexto latinoamericano, algunos autores (Jirón y Mansilla, 2013, entre otros) han subrayado la necesidad de analizar cómo las familias se enfrentan a las degradadas condiciones del hábitat y a una marcada insuficiencia de servicios urbanos (Avellaneda, 2008; Jirón, Imilan e Iturra, 2013; Caggiano y Segura, 2014). Las periferias urbanas de Latinoamérica imponen una gran cantidad de restricciones a sus habitantes, de manera que para ellos será fundamental cómo organicen sus movilidades y viajes para poder satisfacer las más básicas necesidades. Los residentes de estos espacios se ven obligados a desarrollar numerosos y complicados desplazamientos para poder aprovechar los servicios significativos que están ampliamente dispersos en su territorio. 
A la hora de examinar la infraestructura existente, algunos autores (Avellaneda, 2008; Jouffe y Lazo, 2010; Cervero, 2011) han descubierto que los mercados no regulados e informales de transporte pueden ser vitales para estas poblaciones, ante la práctica ausencia de servicios regulados y formales de transporte público. En todos los casos, el acceso a un automóvil es esencial para poder superar las largas distancias (Jacquin, 2007; Rodríguez Vignoli, 2007; Avellaneda, 2008). La ausencia de este tipo de recursos de movilidad, en estos hábitats tan distantes y degradados, suele ser uno de los principales factores de exclusión social para las poblaciones.

Así, se han estudiado las consecuencias que sufren los trabajadores que deben sortear largas distancias en sus viajes cotidianos al trabajo (Rodríguez Vignoli, 2007; Avellaneda, 2008), quienes deben añadir a sus extensas jornadas laborales, varias horas empeñadas en afrontar esos desplazamientos. Para ellos, es muy difícil conciliar sus necesidades laborales con las privadas, lo que suele incidir en altos niveles de estrés y un buen número de conflictos en el hogar (Jacquin, 2012). Como consecuencia de estas tensiones, y para evitar los largos y penosos traslados, se ha señalado que algunas poblaciones alojadas en las periferias prefieren restringir sus desplazamientos a los espacios de mayor proximidad respecto de sus residencias (Rodríguez Vignoli, 2008; Avellaneda y Lazo, 2011; Lazo y Calderón, 2013). Con ello, tratan de aprovechar al máximo los recursos existentes en sus entornos de residencia, o bien desarrollan densas redes sociales de apoyo, compuestas de amigos, familiares o vecinos (Lazo y Calderón, 2013). Ahora bien, se ha indicado que este tipo de anclaje al lugar de residencia evita que las poblaciones establezcan lazos sociales fuera de sus entornos degradados, lo que motiva a la vez que tengan más dificultades para superar su acusada segregación socioespacial (Rodríguez Vignoli, 2007; Lazo y Calderón, 2013).

Estas condiciones de vida tienen implicaciones sustanciales para comprender la constitución social y política que articula las periferias de ciudades latinoamericanas con el resto de la economía urbana. Estas periferias pueden ser comprendidas también como fronteras, espacios sustanciales para la materialización de importantes exclusiones socioespaciales (Sibley, Jackson, Atkinson y Washbourne, 2005) que se expresan por medio de una constante negociación de significados y prácticas (Sidway, 2007). Y esto porque la frontera puede ser entendida como una zona de excepción que distribuye las vidas y los condicionantes vitales de aquellos que pertenecen y de los que no pertenecen a un orden socioeconómico (Dean, 2007). En esa medida, las periferias de las metrópolis latinoamericanas son también espacios donde políticamente se articula un sistema de pertenencia. Los contextos cotidianos de existencia en las periferias metropolitanas no solo expresan largas distancias y viajes, sino también las formas como se estructuran las dependencias respecto de los centros capitalistas, algo que, en otra escala, ha sido convenientemente documentado por los estudios poscoloniales (McEwan, 2009).

Es en este sentido que en este artículo se adopta el término de subordinación para referirse a este tipo de sujetos. En Latinoamérica es extensa la bibliografía que analiza estos grupos sociales, bien en términos de clase social trabajadora (Alonso, 1980), marginadas (Lomnitz, 1993) o pobres (Lewis, 2010). Al utilizar los términos clases y sujetos subordinados se pretende enfatizar esa posición relegada y dependiente en el establecimiento de fronteras de inclusión y exclusión socioterritorial en la urbe contemporánea en relación con la clase social hegemónica, que determina las formas de ocupar y de desplazarse por el territorio. Al mismo tiempo, con esta dupla subordinadohegemónico se quiere resaltar la extensión de grandes consensos sociales que prescriben lo socialmente aceptado (Gramsci, 1981; Laclau y Mouffe, 2001) en términos, en nuestro caso, de desplazarse por el territorio urbano. 
Con estos antecedentes, y pensando en las periferias de las metrópolis latinoamericanas, podemos describir las movilidades periféricas como aquellas que se producen en las fronteras de las principales conurbaciones y que distribuyen las exclusiones socioespaciales en la metrópoli. Así, para entender debidamente su constitución, debemos añadir a la lejanía física los procesos de exclusión socioeconómica. En mi investigación me centraré especialmente en los viajes que se realizan cotidianamente y que sirven para distribuir a la población dentro y fuera del orden socioespacial de una metrópoli latinoamericana.

\section{El Salto como escenificación de las movilidades periféricas}

El Área Metropolitana de Guadalajara es una conurbación en el occidente de México, con 4.7 millones de habitantes, integrada por los municipios de Guadalajara, Zapopan, Tlaquepaque, Tonalá, Tlajomulco y El Salto. El proceso de conurbación ha sido bastante reciente y, en sus últimos estadios, ha incorporado, desde la década de 1990, a los municipios de Tlajomulco y El Salto. Este último se ubica en el sureste de la metrópoli, y colinda con Tonalá hacia el Este, Tlajomulco hacia el Suroeste y Tlaquepaque hacia el Norte. Es el municipio más pequeño del Área Metropolitana, con 172.000 habitantes, y está subdividido en localidades como Las Pintas, Las Pintitas, El Verde, El Quince, El Castillo o la Cabecera Municipal de El Salto. También hay que indicar que El Salto es parte del segundo corredor industrial más grande de México y se prolonga hacia Ocotlán, a 80 kilómetros hacia el Este.

El Salto quedó integrado al Área Metropolitana como resultado indirecto de ciertas políticas de ajuste neoliberal que arrancan desde la década de 1980. Tras el alza del precio del petróleo en 1973 y la aparición de grandes deudas públicas en las economías de la región, México fue forzado a realizar ciertas concesiones en su política económica para poder acceder a la financiación internacional; así, tuvo que enfrentar la venta de bienes y empresas públicas o la reducción de gasto público encaminado a programas gubernamentales redistributivos. En esa tónica, en 1980, el Estado abandonó su labor de garantizar el acceso a la vivienda para las rentas más bajas (Blomley, 2004; Jirón, 2004), y en su lugar generó políticas basadas en el mercado y en la maximización de beneficios inmobiliarios (Zetter, 2004). Estas políticas ocasionaron la incorporación de vastas extensiones de terreno rústico dentro del tejido urbano (Vázquez Castillo, 2004). En México, esta conversión se vehiculó mediante la reforma constitucional de 1992, que permitió la privatización de terrenos comunales o ejidos que habían sido concedidos a los agricultores desde el período posrevolucionario (Vázquez Castillo, 2004).

Desde un análisis de la movilidad residencial, se observa que muchos habitantes de El Salto provienen de colonias de bajos recursos del municipio de Guadalajara, donde se

1. Para el caso chileno puede observarse un proceso similar, según ha sido documentado por Pau Avellaneda y Alejandra Lazo (2011). encontraban próximos a una gran cantidad de servicios y recursos. ${ }^{1}$ Estos sujetos disfrutaban de una gran cantidad de alicientes que ofrecía el entorno urbano consolidado, antes de enfrentarse a un período nómade de cambios residenciales hacia la periferia metropolitana. Después de su migración a El Salto, encontrarían que aquellos recursos urbanos son ahora muy escasos, lo que les generó una impresión de pérdida muy acusada.

Ese primer acercamiento a las poblaciones denota que la capacidad de decidir dónde establecerse en toda esa trayectoria migratoria está ampliamente ausente. En sus hogares de origen, en el municipio de Guadalajara, los por entonces hijos e hijas pasaron a conformar sus propias familias, y se encontraron con grandes dificultades económicas para permanecer en esas colonias u otras aledañas debido al alza de precios inmobiliarios. Como consecuencia, se vieron en cierta medida atrapados en un mecanismo de mercado que progresivamente los estaba expulsando a las periferias de la metrópoli y, en particular, a El Salto. 
En estos casos, la ausencia de capacidad de decisión fue seguida por una omnipresente inestabilidad suscitada por las propias condiciones de los precarios hábitats. La mayoría de los entrevistados proporcionaban una palabra recurrente que resume lo que encontraban en sus nuevos entornos residenciales: "nada". Cuando llegaron no había viviendas, ni habitantes, ni pavimento, ni servicios de agua, ni transporte y, aun procediendo de la ciudad consolidada, ni sentido de la urbanidad. Años después, los habitantes aún recuerdan con cierto pesar el día de su llegada:

Fue un cambio muygrande, porque aquí no teníamos agua, no teníamos luz. Tuvimos que cavar un pozo y yo tenía que tirar con mis propias fuerzas de las cubetas llenas de agua. Fue un cambio muy grande, y al principio fue muy difícil para mí. Me decía a mí misma: 'Vengo de la Monumental (una colonia residencial en el norte de Guadalajara), donde tenía todos los servicios; no había suciedad, había pavimento'. Y ahora era llegar aquí y decirme: 'Ni modo'. Entonces lloraba y le decía a mi madre: 'Mamá, yo no quiero quedarme aqui'. (Ana, servicio doméstico, 52 años, El Verde, 22 de noviembre de 2013)

En contraste con estas condiciones habitacionales, y junto con este entorno tan degradado, la ubicación de El Salto dentro del Corredor Industrial implica la existencia de infraestructura eficiente para mover bienes hacia los mercados internacionales. Si bien la firma del Tratado de Libre Comercio de América del Norte ha implicado la pérdida de empleos y el agravamiento de las condiciones laborales de la población, ha impulsado los intercambios comerciales entre los países implicados (Calderón, 2005), algo que se escenifica de manera privilegiada en el citado corredor. Este tratado ha facilitado que un importante contingente de la producción de la región se oriente hacia el mercado estadounidense. Durante los últimos años, la infraestructura del corredor se ha mejorado considerablemente (Figura 1) para facilitar este tipo de intercambios. Manzanillo, que es el principal puerto en el occidente del país para el comercio con China y el este asiático, se encuentra a 280 kilómetros de El Salto. Por la zona discurre el ferrocarril que, desde esta localidad portuaria, conecta con Estados Unidos a través de Nogales. Además, la Autopista 15 vincula El Salto con Laredo, Texas, once horas hacia el norte. El Aeropuerto Internacional de Guadalajara se ubica a 10 kilómetros de El Salto.



Figura 1. Vías de transporte alrededor de El Salto.

Fuente: Confeccionado por el autor sobre la base del Sistema Cartográfico Nacional del Instituto Nacional de Estadística y Geografía, junio 2016. 
Por último, aunque el transporte público es bastante deficiente, en los últimos tiempos han proliferado empresas privadas de transporte de personal, como BusMen, Tceo, Scott y Zepeda, que permiten a las industrias de El Salto traer puntualmente mano de obra del resto del Área Metropolitana y sus inmediaciones.

En contraste con esta infraestructura para el transporte de mercancías hacia los mercados internacionales, los recursos de transporte para las poblaciones locales son muy escasos. En los últimos 20 años, la inversión en transporte público en el Área Metropolitana de Guadalajara ha sido muy escasa. En 2009 se inauguró la única línea de autobuses de alta capacidad tipo BRT (Bus Rapid Transit) a lo largo de un eje central de la ciudad, la Calzada de Independencia. En la actualidad, se construye una tercera línea del tren ligero, que discurre desde el centro del municipio de Zapopan (uno de los más ricos de México) hacia la estación de autobuses de Guadalajara. Ninguna de estas infraestructuras se extiende hacia periferias como Tlajomulco o El Salto. Por el contrario, las poblaciones alojadas en estos municipios deben confiar en un servicio de autobuses urbanos impuntual y famoso por sus accidentes cotidianos. $\mathrm{Al}$ interior de localidades como El Verde o El Quince, cuya población asciende a casi 34 mil habitantes, solo discurren dos líneas de autobús urbano. Con mucha frecuencia, los autobuses de estas líneas se encuentran repletos de pasaje y no paran a tomar nuevos pasajeros en estas áreas.

También es de notar una ausencia generalizada de infraestructura física e informacional que ayude a las poblaciones periféricas a desplazarse por sus entornos. En el Área Metropolitana de Guadalajara, pero especialmente en su periferia, las paradas de autobús no están claramente demarcadas, de manera que es difícil saber dónde esperar el autobús. Sin señales informativas o marquesinas en las paradas, no se dispone de información sobre los horarios de las unidades o sus rutas. Dado que los servicios de autobús urbano son subcontratados a empresas públicas y privadas, no existen incentivos para sistematizar la información. De esta forma, planificar un viaje complejo a lo largo de la metrópoli puede ser una tarea muy difícil, y los habitantes de la zona en ocasiones restringen sus viajes a través de rutas y a destinos que son bien conocidos. Con ello, la capacidad de explorar mejores opciones y recursos más provechosos se ve ampliamente mermada, y se suprimen las escasas posibilidades de ascenso social.

En El Salto presenciamos la extensión de infraestructuras de transporte que prescriben movilidades diferenciadas. Los factores de producción, como la mano de obra y los insumos de las industrias, quedan eficientemente movilizados a través de la infraestructura existente en el Corredor Industrial. En contrapartida, la población enfrenta muchas dificultades para viajar a lo largo de la periferia metropolitana para solventar sus necesidades domésticas, educativas o de salud.

La ausencia de un eficiente servicio de transporte público en la periferia implica que muchos de sus habitantes tienen que recurrir a soluciones privadas o informales para llegar a sus destinos. En este contexto aparecieron las mototaxis en los vastos complejos habitacionales de Tlajomulco, como Santa Fe o Chulavista. Se trata de motocicletas de tres ruedas cerradas, con asientos traseros para los pasajeros, que sirvieron en un principio para sacar a los habitantes de estos complejos hacia las líneas establecidas de transporte o para desplazarlos hacia los servicios de las inmediaciones, pero que posteriormente se han generalizado en todos los territorios periféricos del Área Metropolitana de Guadalajara.

Alguna de las soluciones que toman los habitantes de la periferia metropolitana es el uso de las bicicletas o motocicletas para llegar a sus destinos (Figura 2). En el contexto del Corredor Industrial, es frecuente ver a familias enteras a bordo de pequeñas motocicletas, o a trabajadores que se trasladan a su trabajo en sus envejecidas bicicletas. 


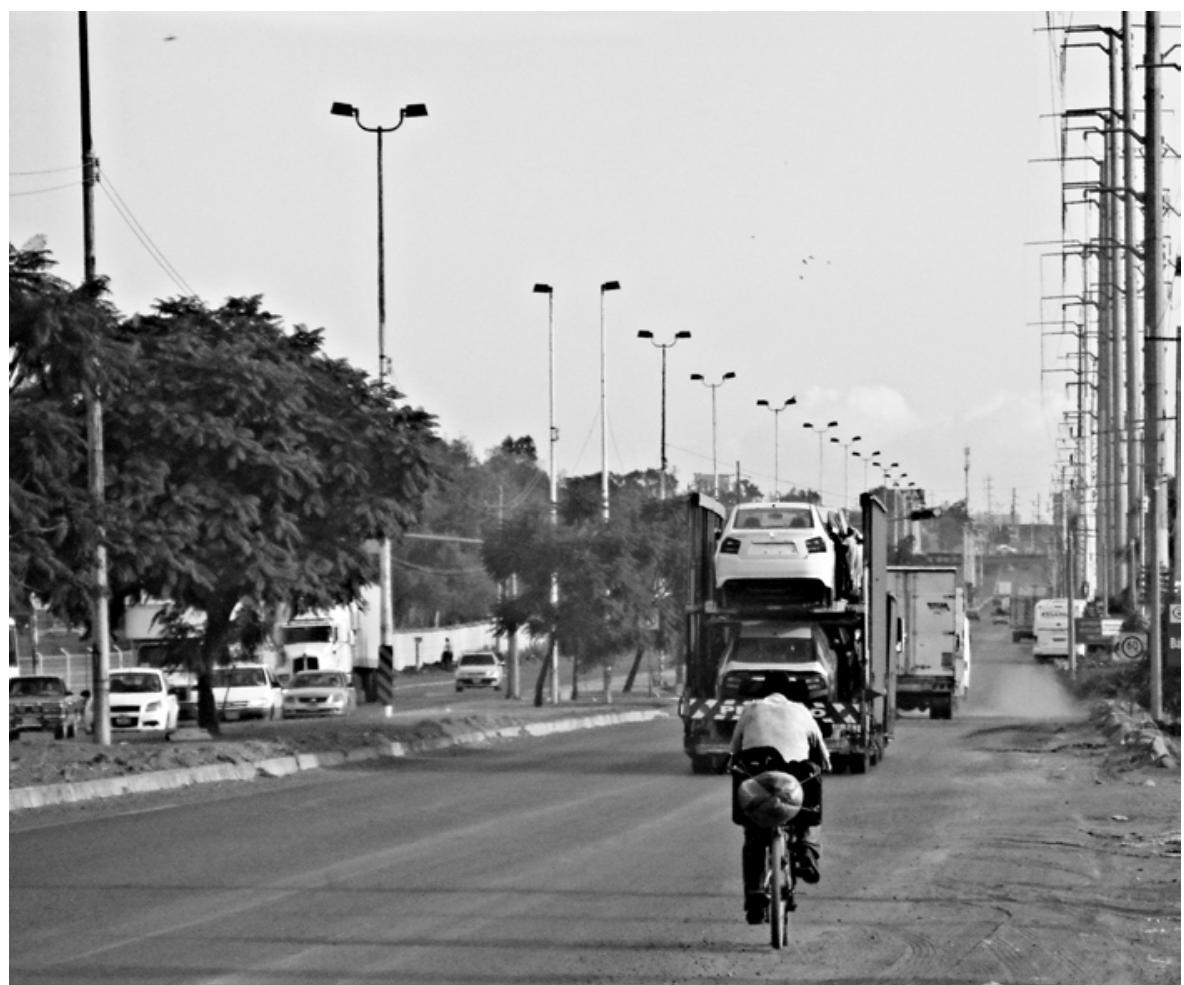

Todos ellos tienen que circular por calles secundarias sin asfaltar y repletas de socavones y grandes charcos de barro, o bien a lo largo de las vialidades principales, compartiendo espacio con el tráfico pesado de tráileres o autobuses de pasajeros. En las entrevistas realizadas en El Salto, es frecuente encontrar testimonios en los que se recuerdan accidentes sufridos en el camino al trabajo.

También hay que recordar que, en las últimas tres décadas, el Área Metropolitana de Guadalajara ha experimentado un patrón de crecimiento disperso y fragmentado. Como ha quedado documentado también en otras metrópolis de la región (Chaves, Segura, Speroni y Cingolani, 2017), algunos integrantes de las clases medias y altas han ubicado sus residencias, centros educativos, hospitalarios, recreacionales y comerciales fuera de la ciudad consolidada. Al mismo tiempo, el automóvil se ha convertido en una herramienta esencial para enfrentarse cotidianamente a las amplias distancias a recorrer que se han generado, lo que lo convirtió en el medio de transporte hegemónico que ha acaparado el grueso de las inversiones realizadas en transporte. La prioridad concedida al automóvil ha incrementado las desventajas de las poblaciones pobres y periféricas. De acuerdo con el censo mexicano (INEGI, 2010), sólo el 44,8\% de los hogares tenía un automóvil en El Salto en 2010, frente al 70,8\% en el enriquecido municipio de Zapopan. Debido al incremento de los costos de operación, en especial el mantenimiento y el precio de las gasolinas, es usual encontrar en El Salto automóviles aparcados en las calles o en los garajes, porque sus propietarios no pueden permitirse usarlos de forma cotidiana. La incapacidad de conducir un automóvil en El Salto supone un obstáculo decisivo que impide a los habitantes involucrarse en procesos de inclusión social a lo ancho de la metrópoli.

Las características del entorno físico con frecuencia refuerzan la falta de accesibilidad. Durante el trabajo de campo de la investigación se documentó la realización de una llamada de emergencia con motivo de un incendio en el fraccionamiento de Jardines del Castillo. Aunque la estación de bomberos más cercana se encuentra a quince minutos de distancia, en la Cabecera Municipal de El Salto, la principal entrada al desarrollo
Figura 2. Ciclista en medio del tráfico del Corredor Industrial de El Salto.

Fuente: Fotografía del autor, octubre de 2015 . 
habitacional se encontraba obstruida por una inundación causada por la rotura de una tubería. En su traslado, el camión de bomberos quedó atrapado en esta gran inundación y la vivienda afectada se quemó enteramente.

Existen otros factores que obstaculizan los desplazamientos en estas zonas periurbanas. Las periferias de la mayor parte de las ciudades mexicanas son conocidas por la presencia de bandas delictivas y por el tráfico de drogas. Los entornos periféricos no solo son inseguros por las degradadas condiciones materiales, sino también por los elevados niveles de asaltos, robos, secuestros, violaciones y asesinatos. La ausencia de seguridad pública en muchos vecindarios restringe las rutas y los viajes disponibles para las poblaciones. Por poner un ejemplo, la Escuela Preparatoria Número 17 de las Pintas, en El Salto, ofrece servicios educativos para las poblaciones circundantes. Sin embargo, muchas de las colonias adyacentes son peligrosas por la presencia del tráfico de drogas y la existencia de pandillas. Para poder llegar a la Preparatoria, los estudiantes se ven obligados a evitar estas colonias y dar largos rodeos. Algunos ni siquiera acuden. Los altos niveles de inseguridad de las periferias constituyen uno de los principales obstáculos para los desplazamientos de las poblaciones y para poder revertir su destino social como integrantes de las clases bajas.

\section{(In)movilidades periféricas, entre la pasividad y la agencia}

Si nos atenemos a la anterior descripción del contexto de El Salto, tendríamos que confirmar la imagen existente sobre el sentido restrictivo, pasivo y deshabilitante de las movilidades de las poblaciones que se ubican en las periferias socioespaciales. Algunos relatos obtenidos confirman esta ausencia de capacidades en la decisión sobre cómo moverse y permanecer. Marta y José son una pareja con dos hijos. José procede de Loma Dorada, en el municipio de Tonalá; y Marta, de una pequeña aldea cercana a Poza Rica, en Veracruz. Se conocieron en Tonalá, comenzaron a frecuentarse, y, sin planificarlo, quedaron embarazados. En un primer momento tuvieron que alojarse en casa de los padres de José, en un pequeño apartamento dentro de Loma Dorada. Cuando nació la segunda hija de la pareja, se les hizo difícil compartir ese reducido espacio con los padres de José, y decidieron comprar una casa propia. Sin embargo, dadas las condiciones del mercado inmobiliario, solo podían permitirse una vivienda en la periferia metropolitana, y compraron finalmente en el fraccionamiento de Jardines del Castillo, en El Salto. Su casa se encuentra dentro de un desarrollo peligroso, por lo que en la actualidad, no permiten a sus hijas de 6 y 3 años jugar fuera de la casa, $o$ entrar y salir libremente. La familia pasa la mayor parte de su tiempo en los escasos 60 metros cuadrados de la vivienda. Solo por las tardes los padres tienen un poco de tiempo libre para salir y acompañar a sus niñas en sus juegos en la calle de atrás.

Mis niñas son todavía pequeñas, y no las podemos dejar solas, igual que pasa con otros padres. La mayor parte del tiempo estamos en la casa, y tengo que quitar mi carro de la cochera para que tengan un poco más de espacio para jugar. Por las tardes salimos y jugamos con ellas en la calle. Pero estamos todo el tiempo vigilándolas, y les decimos que no se vayan lejos, para que podamos vigilarlas. (José, 35 años, jornalero, El Castillo, 4 de diciembre de 2013)

Según el tradicional reparto generizado de actividades dentro de la pareja, Marta se encarga del cuidado del hogar, mientras que José hace su mejor esfuerzo para reunir el ingreso para sostenerlo. En la última depresión económica de 2008, José perdió su trabajo y estuvo desempleado por seis meses. Durante este tiempo, hubo días que solo tenían para comer frijoles. En la actualidad, su situación ha mejorado al encontrar José trabajo en una industria del Corredor Industrial, pero el sueldo no les permite tomar de manera regular el transporte público hacia el Área Metropolitana de Guadalajara. Sin 
la posibilidad de salir, y habiendo dejado en la ciudad consolidada a la familia extensa, pasan la mayor parte de los fines de semana confinados en su residencia.

Estos casos de inmovilidades forzadas son, sin embargo, excepcionales en El Salto. La reducción de la extensión y frecuencia de los viajes no significa necesariamente un confinamiento pasivo. En periferias como El Salto, los habitantes han conseguido anclarse en los territorios, donde desarrollan una gran cantidad de relaciones sociales y familiares. Es habitual encontrar pautas de migración residencial familiares. Buena parte de los migrantes a El Salto decidieron irse al municipio porque algún integrante de sus familias extensas ya se había trasladado allí, o bien planearon cambiarse conjuntamente. Como resultado, en la actualidad es muy frecuente encontrar a padres, hermanos y hermanas viviendo con sus respectivas familias nucleares en el mismo o cercanos vecindarios.

Este es el caso de María, una empleada doméstica de 62 años que vive en la localidad de El Verde. En un tiempo de su trayectoria residencial en que, junto con su esposo, se encontraban viviendo con los padres de ella en Guadalajara, María recuerda una conversación con su hermana. Su hermana había ido a vivir a El Verde cinco años antes, y en aquel momento conocía a un ejidatario que estaba lotificando sus tierras de cultivo, de manera que se presentaba una oportunidad para comprar una parcela donde construir la propia vivienda. En aquel tiempo, María y su hermano, que también estaba buscando vivienda, le preguntaron a su hermana por las condiciones de venta:

\begin{abstract}
Mi hermana le dijo a mi hermano: 'Óscar, deberías ir, porque ahora don Pancho está lotificando'. Y como yo también estaba interesada, de metiche le pregunté: 'Oye, Violeta, ¿yes seguro con ese hombre?' Porque existían un montón de chismes sobre los ejidatarios. Y ella me dijo: 'Sí, es seguro con don Pancho'. Y le dije: 'Porque estoy pensando de ir con él. ¿Qué te parece?’ Y ella me dijo: ‘Ve ahorita, porque aún hay muchos lotes y todavía puedes elegir'. Así que el siguiente domingo fuimos y nos ofreció casi una cuadra entera. (María, empleada doméstica, 62 años, El Verde, 14 de enero de 2014)
\end{abstract}

Un año después de mudarse a El Verde, Óscar, el hermano y su madre se cambiaron también, de manera que pudieron reconstituir la familia extensa, ahora en el extrarradio metropolitano. En estos casos, alejarse del Área Metropolitana de Guadalajara no implica carecer de agencia o de la capacidad para decidir. Al contrario, como se ha señalado para otras ciudades de Latinoamérica (Jouffe, 2011; Lazo y Calderón, 2014), el cambio de residencia hacia la periferia junto con familiares y conocidos es una oportunidad de anclarse en un espacio que ofrece un apoyo y cuidado mutuo. En casos como estos, las familias se reúnen semanalmente, en especial los fines de semana, y juntas celebran cumpleaños y fiestas seculares y religiosas como las navidades, el Día de la Independencia, el Día de la Revolución, el Día de la Virgen de Guadalupe, etc. Estas familias representan casos que, dentro de estrechos límites, deciden permanecer en cierta medida inmovilizados en las periferias para disfrutar de vínculos y del soporte familiar. ${ }^{2}$

Pero también encontramos sujetos que, a pesar de vivir en entornos restrictivos y deshabilitantes, consiguen generar estrategias para acudir a los centros de la metrópoli a disfrutar de sus diversiones. Este es el caso de Julián y su familia. Julián es un descendiente de un anciano ejidatario de El Verde que siempre tuvo mucho cuidado por mantener junta a la familia. De esta forma, la familia extensa se reúne con frecuencia, con motivo de un cumpleaños o cualquier celebración religiosa o laica. Julián ha heredado ese sentido de vivir cerca de la familia extensa, y desde hace dos décadas ha disfrutado de cierta holgura económica que le ha permitido comprar una camioneta. En este amplio automóvil, él y su familia extensa se trasladaban al centro de Guadalajara
2. Como, en un contexto diferente, también han advertido Jamie Gough, Aram Eisenschitz y Andrew McCulloch (2006). 
todos los fines de semana para hacer las compras y divertirse. Con estos viajes a los centros comerciales, los cines o las plazas, compensaban los dispersos y escasos servicios existentes en su localidad.

Con estos desplazamientos, Julián no actúa de manera exclusiva como un actor racional que suple las necesidades de su familia con los viajes al centro. Junto con los fines instrumentales que persigue en estos viajes, también hay otros muy importantes relacionados con la preservación de los vínculos familiares. En 2010 atravesó por problemas financieros temporales, y decidió cambiar su costosa camioneta por un coche más pequeño y más barato. Pronto se arrepintió de su decisión al ver las consecuencias que acarreaba para el clima familiar:

Yo es que tengo tres hijos casados y uno que aún está soltero. Y somos una familia muy unida. Yo siempre he tenido una camioneta, una Blazer. $Y$ en aquel entonces la cambié por un carro más pequeño: un Jetta. ¡Error! ¡No cabíamos! Y entonces se enfadaban: 'No, porque si invitas a tal y cual, entonces no hay lugar para mí'. Fue un gran error. Así que decidí comprar otra camioneta, con tres filas de asientos, y así podemos ir al centro de Guadalajara todos juntos de nuevo. (Julián, empleado público, 48 años, El Verde, 19 de noviembre de 2013)

Lo aquí mostrado matiza la propuesta de entender las movilidades de las poblaciones subordinadas periféricas bajo el esquema "recursos hacia afuera, vínculos hacia adentro" (Segura, 2018, p. 170), según el cual las salidas del entorno de proximidad se realizarían solo para fines instrumentales de satisfacción de alguna necesidad. Este caso presentado muestra cómo los viajes al centro se aprovechan también para hacer familia. Así, Julián demuestra realizar una exploración activa de todo el territorio metropolitano en busca no solo de satisfacer sus necesidades vitales, sino también de forjar y consolidar vínculos familiares.

En El Salto encontramos ejemplos en los que la periferia se constituye también como un espacio repleto de lugares muy significativos y valiosos adonde viajar. No hay que olvidar que esta área, muy recientemente, estaba compuesta por asentamientos rurales, y que aún quedan entornos rurales muy demandados, dadas las exigencias y aglomeraciones de la nueva vida urbana. En ocasiones, como se ha sugerido (Jones, 2004), estos espacios fronterizos suponen una fuente extra de ingresos.

Elena es una mujer nacida en El Castillo que en el momento de la entrevista rondaba los 60 años. Su padre era un jornalero a quien contrataban los ejidatarios de manera ocasional. Elena tuvo tres hermanos y cuatro hermanas, y acompañaba desde joven a su padre a las faenas agrícolas, de manera que, cuando creció, ella misma prosiguió realizándolas. Mientras El Castillo continuó inserto en las dinámicas agrícolas, toda la familia mantuvo ese mismo estilo de vida rural. Sin embargo, tan pronto como se produjo la urbanización de la localidad, Elena y sus familiares tuvieron que cambiar sus empleos y el tipo de vida. Desde la década de 2000, Elena consiguió un trabajo como limpiadora dentro de la administración municipal que le depara el ingreso suficiente para mantener a su hija y a dos nietos que todavía viven con ella.

En El Castillo y sus inmediaciones, repartidas entre las industrias y el tejido urbano, aún persisten algunas parcelas rústicas en situación de barbecho o con plantaciones de maíz. Es frecuente que, en la actualidad, Elena, junto con sus hermanas y algunas sobrinas, se trasladen a estos campos a recoger nopales, chayotes, o a pizcar el maíz sobrante tras la cosecha. Utilizan todos estos productos para su consumo, pero también los venden en los tianguis o mercadillos locales, de forma que complementan los ingresos familiares. Y, como sucedía con Julián, acuden a estas parcelas no solo para satisfacer necesidades económicas: 
Cuando era chica íbamos a pizcar maíz de 6 de la mañana a 8 de la tarde. El dueño nos permitía recoger el maíz y nos decía: 'esta parte va a ser para mí, el resto se la pueden quedar'. Aún hoy hay patrones, los Garcías, que nos permiten ir a pizcar el maíz. Y aún vamos, ya que he terminado de trabajar. Vamos en sábados y domingos a pizcar, ahora que estamos en tiempo de cosecha. Lo recogemos y lo vendemos. Es una tradición que todavía tenemos. Nos gusta ir juntos a recoger nopales también. Nuestro padre nos enseñó a esto, y nosotros todavía lo mantenemos. (Elena, limpiadora, 65 años, El Castillo, 10 de febrero de 2014)

Según observamos más de cerca estas discretas y cotidianas movilidades, encontramos que los habitantes de la periferia no siempre las entienden como un erial del que hubieran de escapar. Existen casos como el de Elena, para quien los viajes de labor en los fines de semana son fundamentales para mantener una tradición e identidad familiares.

Existen otros ejemplos que muestran que algunos habitantes han decidido libremente cambiar sus residencias a El Salto para escapar del ritmo frenético que estaba cobrando Guadalajara, que, en apenas unas décadas, dejó de ser una ciudad parroquiana y se convirtió en una metrópoli global de segundo o tercer orden. Luz ha ayudado a su padre en su tienda de abarrotes desde la década de 1980. Originalmente vivían en la colonia Echeverría, al sur del municipio de Guadalajara. En apenas pocos años, su padre comenzó a cansarse al ver el crecimiento de la ciudad y enfrentar todos los problemas que deparaba: la inseguridad iba en aumento y la proliferación de negocios como el suyo ponía en entredicho las ganancias y los ingresos familiares. De esta forma, a inicios de la década de los 2000, el padre de Luz vendió su tienda para establecer una nueva en El Verde, localidad que prometía un buen número de clientes cautivos dada la ausencia de tiendas similares y el ritmo acelerado de crecimiento poblacional.

Luz permaneció en Guadalajara, ocupada como secretaria en varios negocios pequeños. Como el empleo se hacía más precario y cada vez se encontraba más cansada del nuevo tipo de vida metropolitano, ella misma decidió seguir a su padre y en 2003 se trasladó a El Verde. En esta población volvió a trabajar con él, ayudándolo con la contabilidad de la tienda, y pudo conseguir también un empleo de tiempo parcial en la administración local. Más de diez años después de su traslado a El Verde, valoraba así la tranquilidad que pudo recuperar en esta periferia:

Yo no extraño la ciudad. La gente está harta de vivir en la ciudad, de ese estrés, ese tipo de vida. En Guadalajara no sabes si es de noche o es de día. Porque dices: 'voy a la cama, quiero dormir y descansar'. iPero no descansas! Porque la gente grita, hay demasiados carros, patrullas, sirenas, ruido. Te sientes estresada todo el tiempo. (Luz, empleada pública, 50 años, El Verde, 9 de febrero de 2014)

Este último caso añade otra alternativa al tipo de movilidades que registramos en una periferia como la de El Salto. Junto con los residentes confinados, con los que se reúnen para preservar los vínculos familiares en la periferia, con los que viajan semanalmente al centro urbano para las compras y divertirse o los que acuden a las aún existentes plantaciones para conservar antiguos estilos de vida, encontramos también habitantes que se desplazaron a la periferia para evitar el frenesí de una metrópoli caracterizada por un ritmo de vida y unas movilidades obligatorias que se rechazan.

\section{Conclusiones}

Para encuadrar las movilidades periféricas, en un primer momento, se han considerado las circunstancias del hábitat que condicionan los traslados en el extrarradio metropolitano y, en un segundo término, he revisado algunos casos en que las movilidades de los sujetos 
van desde la pasividad hasta el desarrollo de la libre agencia. Inicialmente se ha descrito un entorno urbano que deparaba oportunidades muy restringidas para la reproducción de los hogares domésticos. La ausencia de servicios y recursos urbanos en el entorno se veía agravada por la ausencia de medios de transporte adecuados o por altos niveles de inseguridad. De este modo, las condiciones del hábitat parecían condenar a las poblaciones locales a vivir situaciones de confinamiento o muy estrechas y pasivas movilidades.

La revisión de casos en El Salto permitió confirmar la existencia de estas situaciones de confinamiento. Sin embargo, otros ejemplos aconsejaban ampliar y complementar estas imágenes iniciales. Se mostraron casos en que las poblaciones decidían anclarse en un territorio de lazos familiares y renunciaban a explorar oportunidades vitales en el grueso del territorio metropolitano; casos en que los sujetos generaban estrategias para suplir la ausencia de servicios y recursos urbanos con viajes semanales al centro urbano; otros en que la periferia misma podía ser también un espacio de recursos tanto económicos como identitarios que permitía sostener estilos de vida tradicionales; y situaciones en que la periferia se constituía en un remanso de vida pausada y tranquila frente a una metrópolis que se hacía cada vez más estresante.

Con todo ello, el artículo se suma a la literatura existente sobre movilidades en las metrópolis de los países en desarrollo que matiza las primeras y excesivamente simplificadoras imágenes existentes sobre las poblaciones subordinadas que se acuñaron desde el paradigma de las movilidades. Así, se señala que las movilidades periféricas no pueden ser reducidas de manera unilateral a la experiencia del confinamiento o de las movilidades forzadas. Según se incrementan las investigaciones, se añade evidencia de que los habitantes en los márgenes de los órdenes socioespaciales extraen múltiples y variadas experiencias de los discretos viajes que desarrollan por el grueso del área metropolitana. En ocasiones, son efectivamente confinados por las condiciones infraestructurales del entorno. Sin embargo, también son relevantes los momentos en que aprovechan esos discretos viajes para obtener enriquecedoras experiencias con sus familias, o los casos en que los sujetos deciden irse a vivir aparte, a la relajación de una periferia que escapa del frenesí de la vida metropolitana contemporánea. En cualquiera de ambas circunstancias, hay que añadir que las movilidades en un espacio fronterizo como la periferia metropolitana mantienen a los sujetos y hogares en los resquicios y márgenes del orden socioespacial de una ciudad ya globalizada y comandada por las elites profesionales y empresariales.

\section{Financiamiento:}

Este artículo se integra dentro de la investigación "El sistema de transportes y la accesibilidad en los municipios del Sur del Área Metropolitana de Guadalajara", que fue financiado por el Consejo Nacional de Ciencia y Tecnología (CONACyT), México, en la Convocatoria de Ciencia Básica 2013.

\section{Agradecimientos:}

El autor quisiera manifestar su agradecimiento a la institución que apoyó financieramente el proyecto que da soporte al artículo.

\section{Biografía:}

Fernando Calonge Reillo es doctor en Sociología por la Universidad Complutense de Madrid. Es profesor investigador del Centro Universitario de Tonalá, Universidad de Guadalajara, México, y pertenece al Sistema Nacional de Investigadores en el nivel I del Consejo Nacional de Ciencia y Tecnología. Su área de investigación es el estudio de las identidades sociales en el espacio urbano. 


\section{Q Referencias bibliográficas}

" Adey, P. (2013). Introduction. Subjects. En P. Adey (Ed.), The Routledge Handbook of Mobilities (pp. 345-348). Londres: Routledge.

"Alonso, J. (1980). Lucha urbana y acumulación de capital. México: La Casa Chata.

" Appadurai, A. (1998). Modernity at Large. Cultural Dimensions of Globalization. Londres: Minnesota University Press.

" Avellaneda, P. (2008). Movilidad cotidiana, pobreza y exclusión social en la ciudad de Lima. Anales de Geografía, 28(2), 9-35.

» Avellaneda, P. y Lazo, A. (2011). Aproximación a la movilidad cotidiana en la periferia pobre de dos ciudades latinoamericanas. Los casos de Lima y Santiago de Chile. Revista Transporte y Territorio, 4, 47-58.

" Bauman, Z. (1998). Globalization. Human Consequences. Cambridge: Polity Press.

» Bauman, Z. (2003). City of Fears, City of Hopes. Londres: Goldsmiths College.

» Blomley, N. (2004). Unsettling the City. Urban Land and the Politics of Property. Nueva York: Routledge.

"Boltanski, L. y Chiapello, E. (2005). The New Spirit of Capitalism. Londres: Verso.

》 Büscher, M. y Urry, J. (2011). Mobile Methods. Nueva York: Routledge.

» Butcher, M. (2011). Cultures of Commuting. The Mobile Negotiation of Space and Subjectivity on Delhi's Metro. Mobilities, 6(2), 237-254.

"Caggiano, S. y Segura, R. (2014). Migración, fronteras y desplazamientos en la ciudad. Dinámicas de la alteridad urbana en Buenos Aires. Revista de Estudios Sociales, 48, 29-42.

»Calderón Salzar, J. (2005). Diez años del TLCAL. Su impacto en la economía de México. En F. Fander (Ed.), TLC. Más que un tratado de libre comercio (pp. 63-106). Quito: Facultad Latinoamericana de Ciencias Sociales.

»Cervero, R. (2011). State Roles in Providing Affordable Mass Transport Services for Low-Income Residents. Leipzig: International Transport Forum.

"Chaves, M., Segura, R., Speroni, M. y Cingolani, J. (2017). Interdependencias múltiples y asimetrías entre géneros en experiencias de movilidad cotidiana en el corredor sur de la Región Metropolitana de Buenos Aires (Argentina). Transporte y Territorio, 16, 41-67.

"Cresswell, T. (2006). On the move. Mobility in the Modern Western World. Londres: Routledge.

»Cresswell, T. y Merriman, P. (2011). Geographies of Mobilities. Practices, Spaces, Subjects. Farnham: Ashgate.

»Dean, K. (2007). The Sites of the Sino-Burmese and Thai-Burmese Boundaries: Transpositions between the Conceptual and Life Worlds. En P. K. Rajaram y C. Grundy-War (Eds.), Hidden Geographies and Politics at Territory's Edge (pp. 183-200). Minneapolis: University of Minnesota Press.

»Edensor, T. (2011). Commuter. Mobility, Rhythm and Commuting. En T. Cresswell y P. Merriman (Eds.), Geographies of Mobilities: Practices, Spaces, Subjects (pp. 189-204). Farnham: Ashgate.

》Elliot, A. y Urry, J. (2010). Mobile Lives. Londres: Routledge. 
» Fada, G., Jirón, P. y Allen, A. (2000). Views from the Urban Fringe. Habitat, Quality of Life and Gender in Santiago, Chile. En M. Jenks y R. Burgess (Eds.), Compact Cities. Sustainable Urban Forms from Developing Countries (pp. 167-182). Londres: Spon Press.

» Freudental-Pedersen, M. (2009). Mobility in Daily Life. Between Freedom and Unfreedom. Farnham: Ashgate.

» García Peralta, B. (2011). Social Housing in Mexico. The Commodification and Peripheral Growth of the City. En T. Kaminer (Ed.), Neoliberal Urbanization (pp. 98-111). Rotterdam: o10 Publishers.

» Gough, J., Eisenschitz, A. y McCulloch, A. (2006). Spaces of Social Exclusion. Londres: Routledge.

» Gramsci, A. (1981). Los cuadernos de la cárcel, t. II. México: Ediciones Era.

" Harvey, D. (1994). Flexible Acumulation through Urbanization: Reflections on Postmodernism in the American City. En A. Amin (Ed.), Post-Fordism. A Reader (pp. 361-386). Oxford: Blackwell.

» Hiernaux, D. y Lindón, A. (2004). Desterritorialización y reterritorialización metropolitana: la ciudad de México. Documents d'Analisi Geografica, 44, 71-88.

» Huq-Hussain, S. y Habiba, U. (2013). Gendered Experiences of Mobility. Travel Behaviour of Middle Class Women in Dhaka City. Transfers, 3(3), 79-98.

» Instituto Nacional de Estadística y Geografía- INEGI (2010). Censo de Población y vivienda. Recuperado de https://www.inegi.org.mx/programas/ccpv/2010/

» Jacquin, C. (2007). El conjunto habitacional Las Américas, un laboratorio para la edificación de una microsociedad. Alteridades, 17(34), 57-73.

» Jacquin, C. (2012). Producir y habitar la periferia. Los nuevos conjuntos de vivienda de bajo costo en México (ZMVM). Bulletin de l'Institut français d'études andines, 41(3), 389-415.

» Jirón, P. (2004). The Beginning of the End of the Chilean Housing Model. Lessons to Be Learned from over 20 Years of Experience. International Conference Adequate $\&$ Affordable Housing for All. Toronto: Centre for Urban and Community Studies. Recuperado de: http://www.urbancentre.utoronto.ca/pdfs/housingconference//iron_Beginning_End.pdf

» Jirón, P. y Mansilla, P. (2013). Atravesando la espesura de la ciudad. Vida cotidiana y barreras de accesibilidad de los habitantes de la periferia urbana de Santiago de Chile. Revista de Geografía Norte Grande, 56, 53-74.

» Jirón, P. y Mansilla, P. (2014). Las consecuencias del urbanismo fragmentador en la vida cotidiana de habitantes de la ciudad de Santiago. EURE, 4O(121), 5-28.

» Jirón, P., Imilan, W. e Iturra, L. (2013). Saber viajar en el metro de Santiago. La apropiación de lo público. Revista Ciudad y Arquitectura, 151, 112-125.

»Jones, G. (2004). Bridging the Rural-Urban Divide. What Can the Urban Learn from the Rural? Reflections on the Case of Mexico. En R. Zetter y M. Hamza (Eds.), Market Economy and Urban Change: Impacts in the Developing World (pp. 123-146). Londres: Earthscan.

» Jouffe, Y. (2011). Las clases socioterritoriales entre movilidad metropolitana y repliegue barrial. ¿Tienen los pobladores una movilidad urbana de clase? Revista Transporte y Territorio, 4, 84-117.

» Jouffe, Y. y Lazo Corvalán, A. (2010). Las prácticas cotidianas frente a los dispositivos de la movilidad. Aproximación política a la movilidad cotidiana de las poblaciones pobres periurbanas de Santiago de Chile. EURE, 36(108), 29-47.

» Kellerman, A. (2006). Personal Mobilities. Nueva York: Routledge. 
"Laclau, E. y Mouffe, C. (2001). Hegemony and Socialist Strategy. Towards a Radical Democratic Politics. Londres: Verso.

» Lazo-Corvalán, A. y Calderón-Sosa, R. (2013). Proximidad y movilidad en la metrópolis contemporánea. Etnografía de tres barrios de la ciudad de Santiago de Chile. Revista Bitácora Urbano Territorial, 22(1), 89-96.

» Lazo, A. y Calderón, R. (2014). Los anclajes en la proximidad y la movilidad cotidiana. Retrato de tres barrios de la ciudad de Santiago de Chile. EURE, 4O(121), 121-14O.

"Lewis, O. (2010). Antropología de la pobreza. Cinco familias. México: Fondo de Cultura Económica.

»Lindón Villoria, A. (1997). De la expansión urbana y la periferia metropolitana. Zinacantepec: El Colegio Mexiquense.

" Lindón, A. (2008). De espacialidades y transnacionalismo. En D. Hiernaux y M. Zárate (Eds.), Espacios y Transnacionalismo (pp. 119-156). México: Universidad Autónoma Metropolitana.

" Lomnitz, L. (1993). Cómo sobreviven los marginados. México: Siglo XXI.

» Manderscheid, K. (2009). Unequal Mobilities. En M. Bergman, T. Ohnmacht, H. Maksim. (Eds.), Mobilities and Inequality (pp. 27-50). Farnham: Ashgate.

» McEwan, C. (2009). Postcolonialism and Development. Nueva York: Routledge.

» Pinder, D. (2011). Cities. Moving, Plugging in, Floating, Dissolving. En T. Cresswell y P. Merriman (Eds.), Geographies of Mobilities. Practices, Spaces, Subjects (pp. 167-188). Farnham: Ashgate.

" Rodgers, D., Beall, J. y Kanbur, R. (2011). Latin American Urban Development in the Twenty-First Century: Towards a Renewed Perspective on the City. European Journal of Development Research, 43(4), 550-568.

» Rodríguez Vignoli, J. (2007). Segregación residencial, migración y movilidad espacial. El caso de Santiago de Chile. Cuadernos Metropole, 17, 135-168.

"Rodríguez Vignoli, J. (2008). Movilidad cotidiana, desigualdad social y segregación residencial en cuatro metrópolis de América Latina. EURE, 34(103), 49-71.

» Rodríguez, J. y Arriagada. C. (2004). Segregación residencial en la ciudad latinoamericana. EURE, 30(89), 5-24.

" Rose, N. (2004). Powers of Freedom. Reframing Political Thought. Cambridge: Cambridge University Press.

"Sabatini, F. y Brain, I. (2008). La segregación, los guetos y la integración social urbana; mitos y claves. EURE, 34(103), 5-26.

"Samanta, G. y Roy, S. (2013). Mobility in the Margins. Hand-Pulled Rickshaws in Kolkata. Transfers, 3(3), 62-78.

"Segura, R. (2018). La ciudad de los senderos que se bifurcan (y se entrelazan): centralidades conflictivas y circuitos segregados en una ciudad intermedia de la Argentina. Universitas Humanística, 85, 155-181.

" Sibley, D. (2003). Geographies of Exclusion. Londres: Routledge.

» Sibley, D., Jackson, P., Atkinson, D. y Washbourne, N. (2005). Cultural Geography: A Critical Dictionary of Key Concepts. Nueva York: I.B. Tauris.

"Sidway, J.A. (2007). The Poetry of Boundaries. En P. K. Rajaram y C. Grundy-War (Eds.), Hidden Geographies and Politics at Territory's Edge (pp. 161-182). Minneapolis: University of Minnesota Press. 
»Soja, E. (2000). Postmetropolis. Critical Studies of Cities and Regions. Oxford: Blackwell.

" Urry, J. (2004). The System of Automobility. Theory, Culture \& Society, 21(4/5), 25-39.

»Urry, J. (2007). Mobilities. Cambridge: Polity Press.

»Vázquez Castillo, M. T. (2004). Land Privatization in Mexico. Urbanization, Formation of Regions and Globalization in Ejidos. Nueva York: Routledge.

»Zetter, R. (2004). Market Enablement and the Urban Sector. En R. Zetter y M. Hamza (Eds.), Market Economy and Urban Change: Impacts in the Developing World (pp. 1-40). Londres: Earthscan. 